\title{
Romain Menini, Rabelais et l'intertexte platonicien
}

\section{Michele Mastroianni}

\section{(2) OpenEdition}

\section{Journals}

\section{Edizione digitale}

URL: http://journals.openedition.org/studifrancesi/6234

DOI: 10.4000/studifrancesi.6234

ISSN: 2421-5856

\section{Editore}

Rosenberg \& Sellier

\section{Edizione cartacea}

Data di pubblicazione: 1 novembre 2010

Paginazione: 540

ISSN: 0039-2944

\section{Notizia bibliografica digitale}

Michele Mastroianni, «Romain Menini, Rabelais et l'intertexte platonicien», Studi Francesi [Online], 162 (LIV | III) | 2010, online dal 30 novembre 2015, consultato il 09 janvier 2021. URL: http:// journals.openedition.org/studifrancesi/6234 ; DOI: https://doi.org/10.4000/studifrancesi.6234

Questo documento è stato generato automaticamente il 9 janvier 2021.

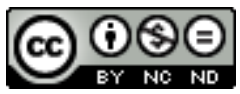

Studi Francesi è distribuita con Licenza Creative Commons Attribuzione - Non commerciale - Non opere derivate 4.0 Internazionale. 


\title{
Romain Menini, Rabelais et l'intertexte platonicien
}

\author{
Michele Mastroianni
}

\section{NOTIZIA}

ROMAIN MENINI, Rabelais et l'intertexte platonicien, Genève, Droz, 2009 («Travaux

d'Humanisme et Renaissance», n. CDLXI), pp. 223.

Platone è forse l'autore più spesso citato da Rabelais. Tuttavia, troppo spesso si è ripetuto che l'umanista cita la sua fonte indirettamente, di seconda se non di terza mano, e pertanto la segnalazione della presenza di Platone si è quasi sempre limitata alle note erudite che hanno accompagnato le varie edizioni. Ora, R. Menini si propone di condurre un'inchiesta sul modo in cui Rabelais «anche quando cita indirettamente Platone è ogni volta inventore della sua fonte». Per far questo usa «tutte le risorse della critica moderna, che possono essere di aiuto nel tentativo di fare rivivere la suddetta 'fonte' platonica sotto la forma, per certo più tecnicamente prosaica, d'un 'intertesto' effettivamente attivo nella trama dialogica del romanzo rabelaisiano». Per valutare nella sua giusta misura l'apporto di Platone alla fiction di Rabelais, l'A. non si limita a repertoriare riferimenti e citazioni dai beaulx dialogues, bensì, partendo dal presupposto che nel Cinquecento il nome di Platone non va mai da solo ma si accompagna a quello dei membri della platonica familia o dei suoi confratelli della prisca theologia, pone la questione del platonismo rabelaisiano nel quadro del sincretismo e neoplatonismo rinascimentale. Pertanto, nella prima parte del suo lavoro («L' 'autorité' de Platon au temps de Rabelais - et dans son texte», pp. 13-61) l'A. ricostruisce in qualche modo il 'mito' Platone nel Rinascimento, sottolineando gli aspetti sincretici delle interpretazioni umanistiche, prima fra tutte quella del neoplatonismo ficiniano. Nella seconda parte («Rabelais et Platon, de Fontenay-le-Comte au Ve livre», pp. 65-129), in una prospettiva diacronica, viene studiata «la scoperta progressiva di Platone da parte di Rabelais e la metamorfosi di questo intertesto privilegiato lungo i diversi periodi della creazione rabelaisiana». Si dimostra, così, che il Platone di Rabelais degli anni 
trenta è molto diverso da quello degli anni quaranta, quando a partire dalla redazione del Tiers livre è il platonismo ficiniano che si sta diffondendo in Francia a impregnare lo scritto rabelaisiano, platonismo che si rivelerà ancor più operante nel Quart livre ( $\mathrm{a}$ volte come reazione irritata agli snobismi venuti d'Italia) quando la diffusione dei testi ficiniani in Francia ha raggiunto il suo culmine. Una terza parte, studiando successivamente il prologo platonico del Gargantua («Les silènes d'Alcofribas», pp.133-154), il capitolo VIII sempre del Gargantua («Le pseudo-'Androgyne’ hièrogliphique de Rabelais», pp.155-177) e passi del Quart livre («L'apologue des fils d'Antiphysie [Quart -livre, XXXII] et autres platonismes», pp.179-200), mette in evidenza come l'intertesto platonico, associato spesso ad altri riferimenti letterari, abbia un ruolo preponderante nella comprensione delle scelte di Rabelais e permette di penetrare meglio nel suo laboratorio intellettuale. 